\title{
Emulsion polymerization of styrene stabilized by mixed anionic and nonionic surfactants
}

\author{
Chorng-Shyan Chern* and Shi-Yow Lin \\ Department of Chemical Engineering, National Taiwan Institute of Technology, Taipei, \\ Taiwan, Republic of China
}

and $\mathrm{Li}-\mathrm{Jen}$ Chen and Shuo-Cheng $\mathrm{Wu}$

Department of Chemical Engineering, National Taiwan University, Taipei, Taiwan, Republic of China

(Received 11 January 1996; revised 25 June 1996)

\begin{abstract}
The mixed SDS/NP-40 (anionic/nonionic) surfactants were used to examine the generality of Smith-Ewart theory which was originally proposed for emulsion polymerization systems containing anionic surfactants. Our results are consistent with Smith-Ewart theory only when the wt $\%$ of NP-40 in the surfactant mixture ([NP-40]) is less than $30 \%$. However, the reaction system deviates from Smith-Ewart theory dramatically when [NP-40] is greater than $50 \%$. The steric stabilization effect provided by pure NP-40 is not strong enough to prohibit the interactive particles from flocculating with one another. On the other hand, the mixed surfactant system can greatly improve the latex stability via the synergetic effects provided by both the electrostatic and steric stabilization mechanisms and, thereby, retard the limited flocculation process. The mixed surfactant system SDS/NP-40 (20/80) is the best, because it results in the best reproducibility of the experiment and the greatest polymerization rate. (C) 1997 Elsevier Science Ltd. All rights reserved.
\end{abstract}

(Keywords: emulsion polymerization; styrene; mixed anionic/nonionic surfactants)

\section{INTRODUCTION}

In the manufacture of latex products, polymer particles are generally stabilized by a mixed surfactant system, an anionic surfactant (e.g. sodium dodecyl sulfate, SDS) in combination with a nonionic surfactant (e.g. nonylphenol40 moles ethylene oxide adduct (NP-40)). The anionic surfactant can impart repulsive forces between similarly charged electric double layers to the latex particles ${ }^{1,2}$, whereas the nonionic surfactant can provide the interactive particles with the steric stabilization mechanism ${ }^{3,4}$. In addition, the nonionic surfactant can improve the chemical and freeze-thaw stability of the latex products. Nowadays, latex products are widely used in coatings, adhesives, plastics and rubber industries.

Conventional micellar nucleation mechanism ${ }^{5-8}$ predicts that the number of latex particles formed during nucleation is proportional to the surfactant concentration to the 0.6 power. Such a relationship is generally valid for emulsion polymerization of relatively waterinsoluble monomers (e.g. styrene, STY) stablized by an anionic surfactant. However, it is unclear whether the micellar nucleation mechanism is still applicable to the case using a mixed surfactant system. Woods et al. ${ }^{9}$ first found that monodisperse latex particles can be prepared by using a mixed surfactant system. In the work of Chu and Piirma ${ }^{10}$, emulsion polymerization of styrene was carried out to study the stabilizing effect of a mixed

\footnotetext{
*To whom correspondence should be addressed
}

surfactant system. They discovered that the latex particles stabilized by a nonionic surfactant alone were less stable and showed a tendency to flocculate with one another during polymerization in comparison with the recipe containing an anionic surfactant. Recently, Unzueta and Forcada ${ }^{11}$ studies the semi-batch seeded emulsion copolymerization of acrylic monomers stabilized by a mixed surfactant system. A similar conclusion to that of $\mathrm{Chu}$ and Piirma was obtained from their experimental work. Chern and coworkers ${ }^{12,13}$ investigated the semi-batch emulsion polymerization of acrylic monomers using SDS/NP-40 as the mixed surfactant system. They showed that the concentration of SDS in the initial reactor charge is the most important parameter in determining the particle size of the latex product. On the other hand, the nonionic surfactant NP-40 is less effective for nucleating and stabilizing the polymer particles, and it only acts as an auxiliary surfactant.

In a previous report ${ }^{14}$, the authors determined the critical micelle concentration (CMC) in an aqueous solution of the mixed surfactant system SDS/NP-40 at both 25 and $80^{\circ} \mathrm{C}$. The $\mathrm{CMC}$ of the SDS/NP-40 solution decreases as the weight percentage of NP-40 in the mixture ([NP-40]) increases, as shown in Figure 1. Furthermore, the CMC of the SDS/NP-40 solution at $80^{\circ} \mathrm{C}$ is slightly higher than that at $25^{\circ} \mathrm{C}$ and the difference diminishes as [NP-40] approaches $100 \%$ (i.e. pure NP-40). These results suggest that at a constant surfactant concentration the number of mixed micelles formed immediately before the start of particle nucleation is 


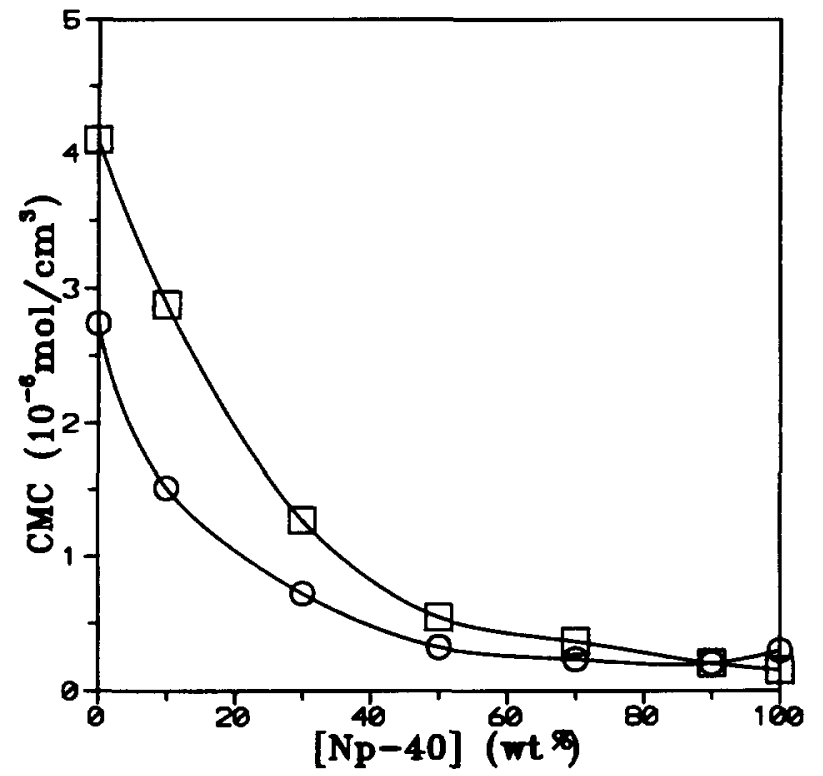

Figure $1 \mathrm{CMC}$ of the SDS/NP-40 solution as a function of the wt $\%$ of $\mathrm{NP}-40$ in the mixture: (O) $25^{\circ} \mathrm{C}$; ( $\square$ ) $80^{\circ} \mathrm{C}$ (ref. 14)

Table 1 A typical recipe for the batch emulsion polymerization of STY $:[S]=6 \times 10^{-3} \mathrm{M},[\mathrm{NP}-40]=50 \%,[\mathrm{I}]=6.43 \times 10^{-3} \mathrm{M}$

\begin{tabular}{|c|c|c|}
\hline & Reagent & Weight $(\mathrm{g})$ \\
\hline Reactor charge & $\left\{\begin{array}{l}\mathrm{H}_{2} \mathrm{O} \\
\mathrm{SDS} \\
\mathrm{NP}-40 \\
\mathrm{STY}\end{array}\right.$ & $\begin{array}{l}80 \\
0.128 \\
0.128 \\
15\end{array}$ \\
\hline Initiator solution & $\left\{\begin{array}{l}\mathrm{H}_{2} \mathrm{O} \\
\mathrm{Na}_{2} \mathrm{~S}_{2} \mathrm{O}_{8}\end{array}\right.$ & $\begin{array}{l}5 \\
0.130\end{array}$ \\
\hline
\end{tabular}

strongly dependent on such parameters as [NP-40], aggregation number of a micelle, and polymerization temperature. This factor can then have a significant influence on the final latex particle size, if the micellar nucleation mechanism predominates during the particle formation stage.

The goal of this project was to investigate the effect of [NP-40] on the parameter $n$ appearing in the following equation for the batch emulsion polymerization of STY:

$$
\log \left(N_{\mathrm{h}}\right)=n \log [\mathrm{S}]+C
$$

where $N_{\mathrm{h}}$ is the number of latex particles per litre of water, that can be calculated according to the hydrodynamic particle size data obtained from the dynamic light scattering method. The parameters $n$ and $C$ are the slope and intercept of the least-squares-best-fitted log $\left(N_{\mathrm{h}}\right)$ vs $\log [\mathrm{S}]$ straight line, and [S] is the total surfactant concentration. For example, the parameter $n$ is equal to 0.6 for the polymerization system that follows SmithEwart theory ${ }^{6,7}$. STY was the monomer used throughout this work because, as mentioned above, batch emulsion polymerization of such a hydrophobic monomer follows Smith-Ewart theory. In addition, it is very interesting to study the effectiveness of the mixed sufactant system in stabilizing the polymer particles during the reaction.

\section{EXPERIMENTAL}

The chemicals used in the work include STY (Taiwan Styrene Monomer Co.), SDS (Henkel Co.), NP-40

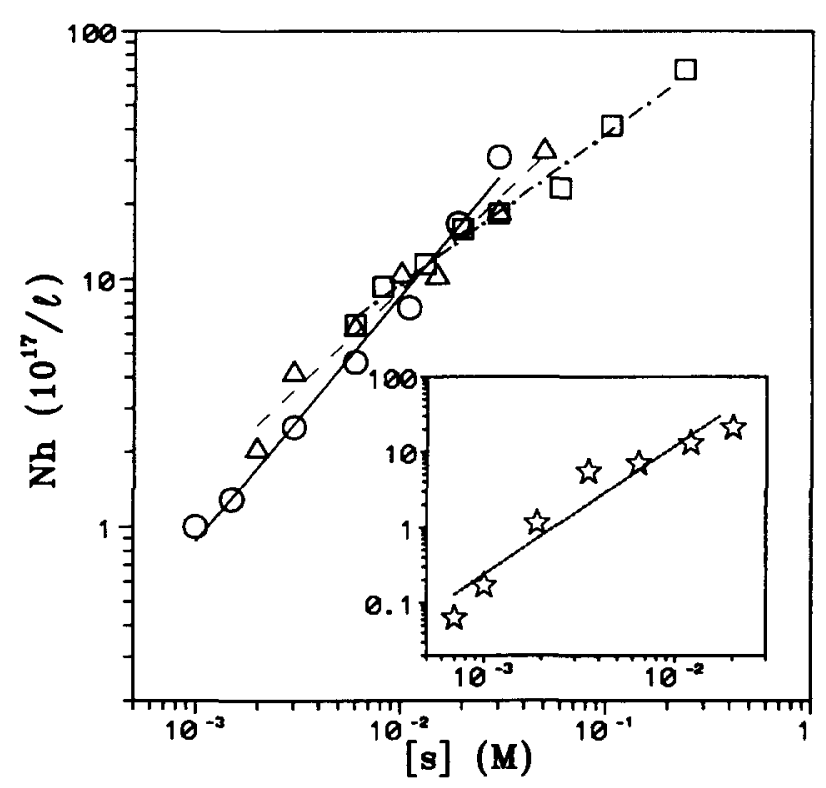

Figure 2 Number of latex particles per litre of water as a function of the total surfactant concentration: $[\mathrm{NP}-40]=(\square,-\cdot-) 0 \% ;(\triangle,---)$ $50 \% ;(\mathrm{O}, \longrightarrow) 100 \%$; Inset: $[\mathrm{NP}-40]=(\hat{k}, \ldots \ldots) 80 \%$

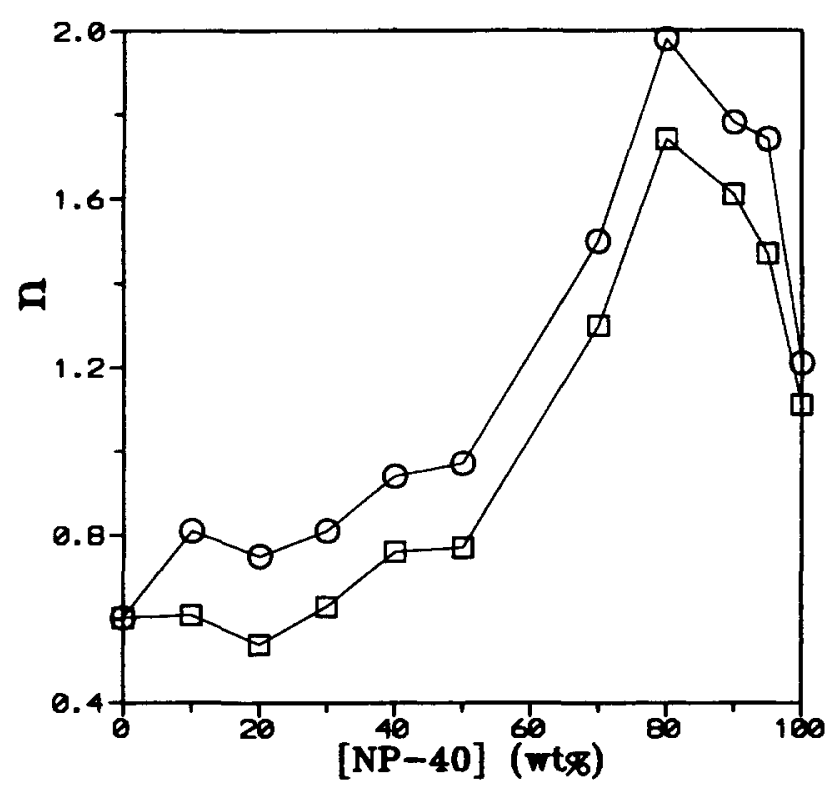

Figure 3 Smith-Ewart parameter $n$ obtained from the slope of the least-squares-best-fitted $\log \left(N_{\mathrm{h}}\right)$ vs $\log [\mathrm{S}]$ straight line as a function of the wt \% of NP-40 in the mixture: $(\square) N_{\mathrm{h}} ;(0) N_{\mathrm{g}}$

(Union Carbide), sodium persulfate (Riedel-de-Haen), nitrogen (Ching-Feng-Harng Co.), and deionized water (Barnsted, Nanopure Ultrapure Water System, specific conductance $<0.057 \mu \mathrm{S} \mathrm{cm}^{-1}$ ). The monomer STY was distilled under reduced pressure before use. All other chemicals were used as received.

Batch emulsion polymerization was carried out in a $250 \mathrm{ml}$ glass reactor equipped with a four-bladed fan turbine agitator, a thermometer, and a reflux condenser. A typical recipe is shown in Table 1 . The total solids content was designed at $15 \%$. First, water, SDS/NP-40, and STY were charged to the reactor and the reactor charge was purged with nitrogen for $10 \mathrm{~min}$ to remove dissolved oxygen while heated to $80^{\circ} \mathrm{C}$, followed by addition of the initiator solution to initiate the reaction. The polymerization was carried out at $80^{\circ} \mathrm{C}$ over $4 \mathrm{~h}$. 

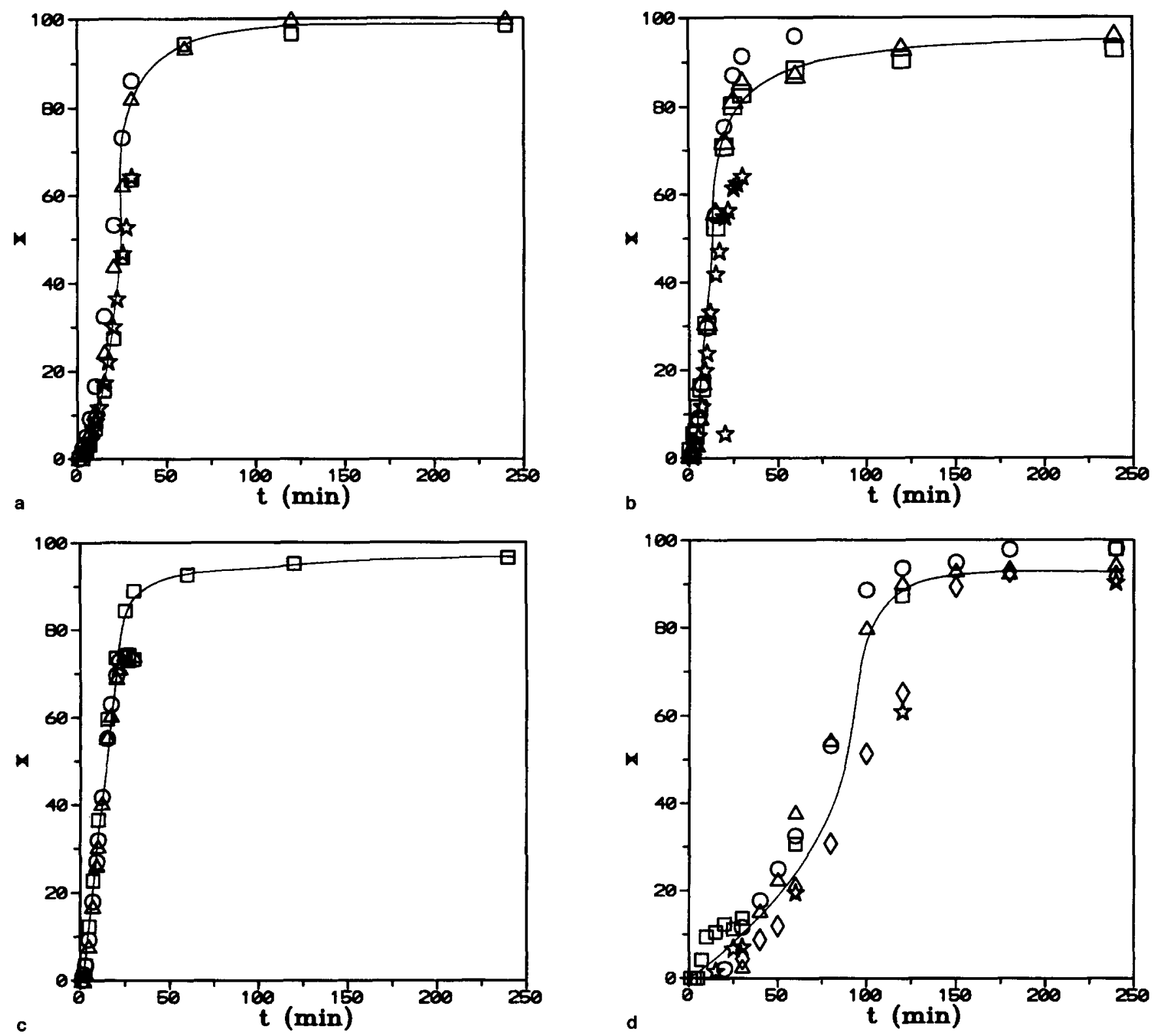

Figure 4 Monomer conversion as a function of the reaction time: [NP-40] $=$ (a) $0 \%$; (b) $50 \%$; (c) $80 \%$; (d) $100 \%$

The finished latex product was filtered through a $40-$ mesh $(0.42 \mathrm{~mm})$ and a 200 -mesh $(0.074 \mathrm{~mm})$ screen in series to collect the filterable solids. Scrap adhering to the agitator, thermometer, and reactor wall was also collected. Most of the finished batches showed relatively low levels of coagulum. The total solid content of the latex sample was determined by the gravimetric method. Particle size data were obtained from the dynamic light scattering method (Otsuka, Photal LPA-3000/3100).

\section{RESULTS AND DISCUSSION}

\section{Effect of [NP-40] on the parameter $\mathrm{n}$}

In this series of experiments, the concentration of initiator $([\mathrm{I}])$ was kept constant $\left(6.43 \times 10^{-3} \mathrm{M}\right)$. Figure 2 shows typical $N_{\mathrm{h}}$ vs [S] data in logarithmic scale for the experiments with [NP-40] equal to $0 \%$ (pure SDS), $50 \%$, $80 \%$ and $100 \%$ (pure NP-40), respectively. At a fixed [NP-40], the number of latex particles per litre of water $\left(N_{\mathrm{h}}\right)$ produced at the end of polymerization is correlated well with the total surfactant concentration ([S]) according to equation (1), and the parameter $N_{\mathrm{h}}$ increases with an increase in [S]. The slopes of the least-squares-bestfitted straight lines in Figure 2 and other experiments with various levels of [NP-40] (data not shown here) are shown in Figure 3. The parameter $n$ first remains relatively constant ( $\mathrm{ca}$ 0.6) when [NP-40] is increased from 0 to $30 \%$, followed by a rapid increase in $n$ to a maximum with [NP-40] being increased from 30 to $80 \%$. The parameter $n$ then decreases rapidly as [NP-40] is increased from 80 to $100 \%$. Also illustrated in Figure 3 are the calculated slopes $(n)$ based on the $\log \left(N_{\mathrm{g}}\right)$ vs $\log [\mathrm{S}]$ data. In this case, the parameter $N_{\mathrm{g}}$ represents the number of latex particles per litre of water that can be calculated according to the dynamic light scattering particle size data corrected with NP-40 adsorption layer thickness (ca $7.3 \mathrm{~nm})^{15}$. These $n$ vs [NP-40] data also show similar trends. Thus, it can be concluded that Smith-Ewart theory is only valid for the STY emulsion polymerization system when [NP-40] is less than $30 \mathrm{wt} \%$. On the other hand, the polymerization system starts to 

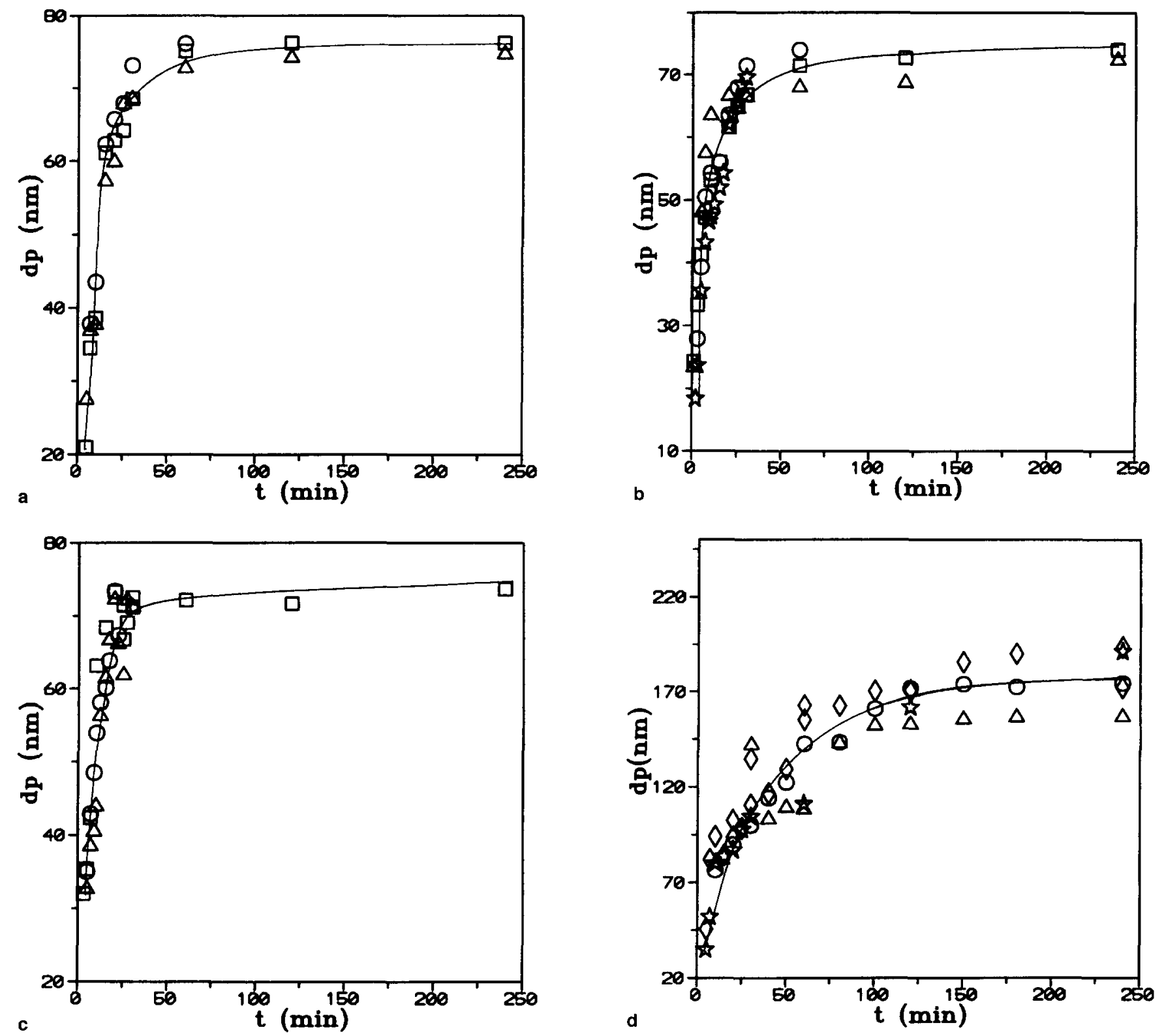

Figure 5 Particles size as a function of the reaction time: $[\mathrm{NP}-40]=$ (a) $0 \% ;$ (b) $50 \% ;$ (c) $80 \% ;$ (d) $100 \%$

deviate from Smith-Ewart theory dramatically when [NP-40] is greater than $50 \%$. The largest deviation appears at $[\mathrm{NP}-40]=80 \%$, where the parameter $n$ is as high as 1.8 . It should be noted that the greater the value of $n$, the more sensitive is the final latex particle size $\left(d_{\mathrm{p}}\right)$ to small changes in the total surfactant concentration. As a consequence, this factor can make the task of particle size control more difficult in plant production.

\section{Effect of $[N P-40]$ on $\mathrm{N}_{h}$ or $\mathrm{N}_{g}$ at $[S]=6 \times 10^{-3} \mathrm{M}$}

Four experiments with [NP-40] equal to $0,50,80$ and $100 \%$, respectively, were then selected to further study the role of the mixed surfactant system in stabilizing the growing latex particles during polymerization. In this series of experiments, the total surfactant concentration ([S]) and the initiator concentration ([I]) were kept constant at $6 \times 10^{-3} \mathrm{M}$ and $6.43 \times 10^{-3} \mathrm{M}$, respectively. This value of $[\mathrm{S}]$ is about 1.5 times the $\mathrm{CMC}\left(80^{\circ} \mathrm{C}\right)$ of the pure SDS solution, and it is always higher than the CMCs $\left(80^{\circ} \mathrm{C}\right)$ of the mixed surfactant solutions with various levels of [NP-40] (see Figure 1). Each experiment was carried out several times to study its reproducibility in terms of the monomer conversion $(X)$ and particle size $\left(d_{\mathrm{p}}\right)$ data. The $X$ vs time profiles for the experiments with [NP-40] equal to 0 (pure SDS), 50, 80 and $100 \%$ (pure NP-40), respectively are shown in Figure 4 . The corresponding $d_{\mathrm{p}}$ vs time profiles for the experiments with [NP-40] equal to $0,50,80$ and $100 \%$, respectively, are shown in Figure 5.

Both the monomer conversion $(X)$ and particle size $\left(d_{\mathrm{p}}\right)$ data taken during polymerization show that the reproducibility of the experiment in the decreasing order is: $[\mathrm{NP}-40]=80 \% \approx[\mathrm{NP}-40]=0 \%>[\mathrm{NP}-40]=50 \% \gg$ $[\mathrm{NP}-40]=100 \%$. For the reaction system stabilized by pure NP-40, the extremely scattered data are attributed to the relatively unstable latex particles since the nonionic surfactant with a concentration of $6 \times 10^{-3} \mathrm{M}$ is not sufficient to protect the growing particles from flocculating with one another (see Figures $4 d$ and $5 d$ ). On the other hand, the mixed surfactant system containing $20 \mathrm{wt} \%$ SDS or more can be very effective for stabilizing the growing latex particles in the course of polymerization. 
Consequently, the reproducibility of these experimental data is reasonably good (see Figures $4 a-4 c$ and $5 a-5 c$ ). Furthermore, it takes about $2 \mathrm{~h}$ for the polymerization system stabilized by pure NP-40 to achieve $90 \%$ monomer conversion. On the other hand, the polymerization systems with [NP-40] less than $80 \%$ can reach $90 \%$ monomer conversion within only $1 \mathrm{~h}$. The slower polymerization rate for the formulation containing pure NP-40 is due to the smaller number of latex particles (i.e. reaction loci) formed during the particle nucleation period and/or the more intensive limited flocculation process taking place during the particle growth period. Such a limited flocculation process involves the tremendous particle surface area generated during the particle nucleation period and, consequently, the concentration of NP-40 adsorbed on the particle surface is not high enough to provide the interactive particles with adequate steric stabilization. Therefore, the latex particles can grow in size by mild aggregation of a few particles. This action will lead to a decrease in the number of latex particles (i.e. a reduction in the total particle surface area) and, hence, increase the particle surface coverage density of NP-40. The flocculation process will diminish when the particle surface coverage density increases to a certain level and most of the flocculated particles still can be stably dispersed in water. These observations are consistent with the work of Chu and Piirma ${ }^{10}$, Unzueta and Forcada ${ }^{11}$ and Chern and coworkers ${ }^{12,13}$.

The rate of polymerization $\left(R_{\mathrm{p}}\right)$ for emulsion polymerization can be written as

$$
R_{\mathrm{p}}=[\mathrm{M}]_{0} \mathrm{~d} X / \mathrm{d} t=K_{\mathrm{p}}[\mathrm{M}]_{\mathrm{p}}\left(\bar{n} N_{\mathrm{h}} / N_{\mathrm{a}}\right)
$$

where $K_{\mathrm{p}}$ is the propagation rate constant, $[\mathrm{M}]_{0}$ is the initial concentration of monomer based on total water (i.e., $1.697 \mathrm{M}$ in this work), $[\mathrm{M}]_{\mathrm{p}}$ is the concentration of monomer in the particles, $\bar{n}$ is the average number of free radicals per particle, and $N_{\mathrm{a}}$ is Avogadro's number. This equation can be used to calculate $\bar{n}$ if the parameters $R_{\mathrm{p}}$,

Table 2 Kinetic parameters for batch emulsion polymerization of styrene at $80^{\circ} \mathrm{C}$

\begin{tabular}{lcll}
\hline Parameter & Numeric value & Units & References \\
\hline$f$ & 1 & & \\
$K_{\mathrm{d}}$ & $1.10 \times 10^{-4}$ & $\mathrm{~s}^{-1}$ & 17 \\
$K_{\mathrm{p}}$ & 342 & $1 \mathrm{~mol}^{-1} \mathrm{~s}^{-1}$ & 18 \\
$K_{\mathrm{tp}}$ & $5.81 \times 10^{7}$ & $1 \mathrm{~mol}^{-1} \mathrm{~s}^{-1}$ & 19 \\
$K_{\mathrm{d}}^{\prime}\left(60^{\circ} \mathrm{C}\right)$ & $6 \times 10^{-12}$ & $\mathrm{~cm}^{2} \mathrm{~s}^{-1}$ & 20 \\
{$[\mathrm{M}]_{\mathrm{p}}$} & 5.2 & $\mathrm{~mol} \mathrm{l}^{-1}$ & 21 \\
$m(\mathrm{SDS})$ & 71 & & 22,23 \\
$m(\mathrm{NP}-40)$ & 8 & & 24 \\
\hline
\end{tabular}

$K_{\mathrm{p}},[\mathrm{M}]_{\mathrm{p}}$, and $N_{\mathrm{h}}$ are known. During Smith-Ewart Interval II, $R_{\mathrm{p}}$ remains relatively constant because of the steady values of $[\mathrm{M}]_{\mathrm{p}}, \bar{n}$, and $N_{\mathrm{p}}$ and $X$ is approximately in the range of $15-45 \%$ for STY ${ }^{16}$. The rate of polymerization can be calculated according to the relationship $R_{\mathrm{p}}=[\mathrm{M}]_{0} \mathrm{~d} X / \mathrm{d} t$. in which $\mathrm{d} X / \mathrm{d} t$ is simply the slope of the least-squares-best-fitted $X$ vs $t$ straight line during Interval II. The parameters $K_{\mathrm{p}}$ and $[\mathrm{M}]_{\mathrm{p}}$ obtained from the literature are listed in Table 2. The calculated $R_{\mathrm{p}}$ and $\bar{n}$ as a function of [NP-40] are shown in Table 3. It is interesting to note that the $R_{\mathrm{p}}$ data display a maximum for the polymerization system with $[\mathrm{NP}-40]=80 \%$. Furthermore, the parameter $\bar{n}$ increases with increasing [NP-40] and only the polymerization system with $[\mathrm{NP}-40]=50 \%$ follows Smith-Ewart case II kinetics (i.e. $\bar{n}=0.5)^{6}$.

The parameter $\bar{n}$ thus obtained can be used to estimate the rate of absorption of radicals by particles $\left(R_{\mathrm{a}}\right)$ as a function of [NP-40] according to the O'Toole equation if the termination reaction in the aqueous phase is insignificant $^{25}$ :

$$
\bar{n}=a / 4\left[I_{m}(\mathrm{a}) / I_{m-1}(a)\right]
$$

where $a=(8 \alpha)^{1 / 2}$ and $I_{m}$ and $I_{m-1}$ are the Bessel functions of the first kind of order $m$ and $m-1$, respectively. The parameters $a=R_{\mathrm{a}} V_{\mathrm{p}} / K_{\mathrm{tp}} N_{\mathrm{h}}$ and $m=K_{0} a_{\mathrm{p}} / K_{\mathrm{tp}}$ are the dimensionless groups related to absorption of radicals by particles and desorption of radicals from particles, respectively. The term $V_{\mathrm{p}}$ is the volume of a monomer-swollen particle, $K_{\mathrm{tp}}$ is the termination rate constant in the particle phase, $K_{0}$ is the specific desorption rate constant, and $a_{\mathrm{p}}$ is the surface area of a monomer-swollen particle. The parameter $K_{0}\left(\mathrm{~cm} \mathrm{~s}^{-1}\right)$ is related to the desorption rate constant $K_{\mathrm{d}}^{\prime}\left(\mathrm{cm}^{2} \mathrm{~s}^{-1}\right)$, which is independent of $d_{\mathrm{p}}$, by the following equation ${ }^{26}$ :

$$
K_{0} a_{\mathrm{p}} / V_{\mathrm{p}}=K_{\mathrm{d}}^{\prime} /\left[(\pi / 6)^{\frac{2}{3}} d_{\mathrm{p}}^{2}\right]
$$

Note that the theoretical value of $K_{\mathrm{d}}^{\prime}$ at $60^{\circ} \mathrm{C}$ listed in Table 2 is about one order of magnitude greater than the experimental data ${ }^{20}$. Thus, it is reasonable to use this value of $K_{\mathrm{d}}^{\prime}$ to compute $\alpha$ and $R_{\mathrm{a}} / R_{\mathrm{i}}$ at $80^{\circ} \mathrm{C}$ since the $K_{\mathrm{d}}^{\prime}$ data at $80^{\circ} \mathrm{C}$ are not available in the literature. The ratio $R_{\mathrm{a}} / R_{\mathrm{i}}$ represents the fraction of free radicals produced in water that is absorbed by the latex particles, in which the term $R_{\mathrm{i}}=2 f K_{\mathrm{d}}[\mathrm{I}]$ is the generation rate of free radicals in the aqueous phase, $f$ is the initiation efficiency factor, $K_{\mathrm{d}}$ is the initiator decomposition rate constant, and [I] is the initiator concentration.

The calculated $\alpha$ and $R_{\mathrm{a}} / R_{\mathrm{i}}$ for various values of [NP40] are summarized in Table 3 . The rate of absorption of

\begin{tabular}{|c|c|c|c|c|}
\hline & \multicolumn{4}{|c|}{$[\mathrm{NP}-40](\%)$} \\
\hline & 0 & 50 & 80 & 100 \\
\hline$N_{\mathrm{h}}\left(1^{-1}\right)^{a}$ & $6.56 \times 10^{17}$ & $6.50 \times 10^{17}$ & $7.26 \times 10^{17}$ & $4.63 \times 10^{16}$ \\
\hline$d_{\mathrm{p}}(\mathrm{nm})^{b}$ & 61.3 & 53.9 & 49.0 & 129.9 \\
\hline$R_{\mathrm{p}}\left(\mathrm{moll}^{-1} \mathrm{~s}^{-1}\right)$ & $5.77 \times 10^{-4}$ & $9.28 \times 10^{-4}$ & $1.25 \times 10^{-3}$ & $1.11 \times 10^{-4}$ \\
\hline $\bar{n}$ & 0.30 & 0.48 & 0.59 & 0.81 \\
\hline$\alpha$ & $2.26 \times 10^{-4}$ & $3.55 \times 10^{-3}$ & $1.81 \times 10^{-1}$ & $7.70 \times 10^{-1}$ \\
\hline$R_{\mathrm{a}} / R_{\mathrm{i}}$ & $1.40 \times 10^{-1}$ & $3.22 \times 10^{0}$ & $2.18 \times 10^{2}$ & $5.00 \times 10^{1}$ \\
\hline
\end{tabular}
radicals by particles $\left(R_{\mathrm{a}}\right)$ is slower than or comparable

Table 3 Calculated values of $\bar{n}, \alpha$, and $R_{\mathrm{a}} / R_{\mathrm{i}}$ as a function of [NP-40]: $[\mathrm{S}]=6 \times 10^{-3} \mathrm{M}$ and $[\mathrm{I}]=6.43 \times 10^{-3} \mathrm{M}$

\footnotetext{
${ }^{a}$ Number of particles at the end of polymerization

${ }^{b}$ Particle size at a monomer conversion of $30 \%$
} 
to the generation rate of radicals in water $\left(R_{\mathrm{i}}\right)$ when [NP-40] is below $50 \%$. On the other hand, the ratio $R_{\mathrm{a}} / R_{\mathrm{i}}$ is unusually high when [NP-40] is above $80 \%$. The maximum $R_{\mathrm{a}} / R_{\mathrm{i}}(218)$, again, occurs at $[\mathrm{NP}-40]=80 \%$. It seems that the polymerization systems with $[\mathrm{NP}-40]>80 \%$ cannot be adequately described by the conventional O'Toole's equation. The reason for such a physically unreasonable situation (i.e., $R_{\mathrm{a}} \gg R_{\mathrm{i}}$ ) associated with the polymerization system with [NP-40] $>80 \%$ is not clear at this point of time. One possible explanation is that termination of radicals in the particle phase and/or desorption of radicals from particles are greatly retarded for the polymerization system with $[\mathrm{NP}-40]>80 \%$. This postulation can lead to a value of $\bar{n}$ greater than 0.5 without resorting to an impractical ratio of $R_{\mathrm{a}} / R_{\mathrm{i}}$.

Figure 6 shows the $N_{\mathrm{h}}$ (or $N_{\mathrm{g}}$ ) vs [NP-40] curves when the total surfactant concentration is a constant $\left([S]=6 \times 10^{-3} \mathrm{M}\right)$. The experimental data show that the number of latex particles produced remains relatively constant when [NP-40] is in the range of $0-90 \%$, and it drops sharply when [NP-40] is increased from 90 to $100 \%$. This trend, again, supports the above postulation that the nonionic surfactant NP-40 is less effective for stabilizing the growing particles during the reaction.

Let us consider the above two emulsion polymers stabilized by pure SDS or NP-40. Neglecting the monomer effect, the number of micelles $\left(N_{\mathrm{m}}\right)$ formed just before the start of polymerization can be estimated by the following equation:

$$
N_{\mathrm{m}}=\left([\mathrm{S}]-\mathrm{CMC}\left(80^{\circ} \mathrm{C}\right)\right) / m
$$

were $m$ is the number of surfactant molecules present in a micelle (i.e. aggregation number). Thus, the number of free radicals captured by one micelle is equal to $R_{\mathrm{i}} / N_{\mathrm{m}}$. The kinetic parameters used in the calculation of $R_{\mathrm{i}} / N_{\mathrm{m}}$ are listed in Table 2. The calculated values of the parameters $N_{\mathrm{m}}, R_{\mathrm{i}} / N_{\mathrm{m}}$, and $N_{\mathrm{h}}$ are summarized in Table 4. Theoretical analysis on the experiments with intermediate surfactant compositions (i.e. $0<[\mathrm{NP}-40]<100 \%$ ) was not conducted here because the information about the mixed micelles (such as the structure, composition, and aggregation number $(m)$ ) required for calculation is not available at this point of time.

At a constant initiator concentration $([\mathrm{I}]=$ $\left.6.43 \times 10^{-3} \mathrm{M}\right)$, the number of micelles $\left(N_{\mathrm{m}}\right)$ formed in the reaction system stabilized by pure NP-40 is about 27 times greater than that formed in the system stabilized by pure SDS, as shown in Table 4. Nevertheless, the number of latex particles per litre of water $\left(N_{\mathrm{h}}\right)$ produced in the former system is only $7 \%$ of that produced in the latter system. One possible explanation for this contradiction is that the capture rate of free radicals by the micelles in the NP-40 stabilized polymerization system is only $4 \%$ of that in the SDS stabilized system during the particle nucleation stage (see the calculated $R_{\mathrm{i}} / N_{\mathrm{m}}$ data in Table 4 ).
As a result, a large proportion of the NP-40 micelles do not participate in the particle nucleation process. To check this postulation, one experiment with $[\mathrm{S}]=6 \times 10^{-3} \mathrm{M}$, $[\mathrm{NP}-40]=100 \%$, and $[\mathrm{I}]=1.78 \times 10^{-1} \mathrm{M}$ was carried out and the results are also included in Table 4. In this case, the NP-40 stabilized polymerization system has the same level of $R_{\mathrm{i}} / N_{\mathrm{m}}$ as the SDS stabilized system. The resultant $N_{\mathrm{h}}$ produced in the NP-40 stabilized system is still only $24 \%$ of that produced in the SDS stabilized system, even though the former system contains many more micelles than the latter system. This result strongly suggests that not all the nucleated primary particles can survive the limited flocculation process taking place in the course of polymerization when the nonionic surfactant NP-40 is used as the sole stabilizer.

Effect of $[N P-40]$ on $\mathrm{N}_{h}$ or $\mathrm{N}_{g}$ at $[S]=2 \times C M C\left(80^{\circ} \mathrm{C}\right)$

In this series of experiments, the total surfactant concentration ([S]) was kept at twice the CMC $\left(80^{\circ} \mathrm{C}\right)$ of the mixed surfactant system and the initiator concentration was kept constant $\left([\mathrm{I}]=6.43 \times 10^{-3} \mathrm{M}\right)$. The $N_{\mathrm{h}}$ (or $N_{\mathrm{g}}$ ) vs [NP-40] data are shown in Figure 7. The number of latex particles per litre of water first remains relatively constant when [NP-40] is below $30 \%$ and, thereafter, it starts to decrease with an increase in [NP-40]. Finally, Table 5 lists the calculated parameters $N_{\mathrm{m}}, R_{\mathrm{i}} / N_{\mathrm{m}}$, and $N_{\mathrm{h}}$ for the two emulsion polymers stabilized by pure SDS and NP-40, respectively. These two experiments have comparable values of $N_{\mathrm{m}}$ and $R_{\mathrm{i}} / N_{\mathrm{m}}$. Under such a condition, one might expect that both runs will result in similar numbers of latex particles per litre of water $\left(N_{\mathrm{h}}\right)$ if the limited flocculation process is insignificant in the course of polymerization. However, as shown in Table 5 ,

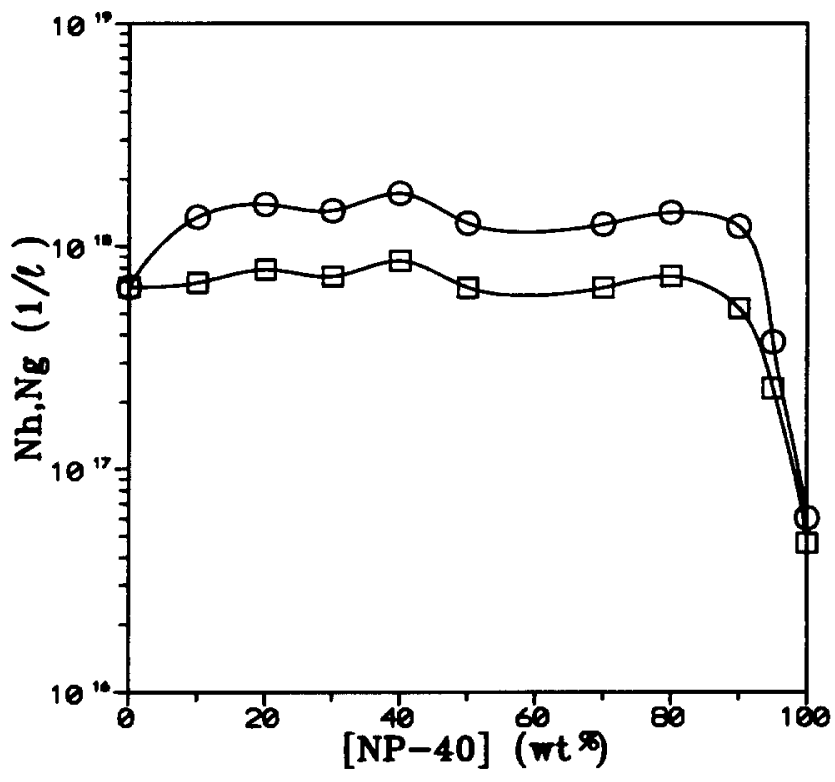

Figure 6 Number of latex particles per litre of water as a function of the wt $\%$ of NP-40 in the mixture: $[\mathrm{S}]=6 \times 10^{-3} \mathrm{M}$. (口) $N_{\mathrm{h}}$; (O) $N_{\mathrm{g}}$

Table 4 Calculated values of the parameters $N_{\mathrm{m}}, R_{\mathrm{i}} / N_{\mathrm{m}}$, and $N_{\mathrm{h}}$ : $[\mathrm{S}]=6 \times 10^{-3} \mathrm{M}$

\begin{tabular}{lllll}
\hline Surfactant & {$[\mathrm{I}](\mathrm{M})$} & $\mathrm{CMC}(\mathrm{M})$ & $N_{\mathrm{m}}(\mathrm{M})$ & $N_{\mathrm{h}}(\mathrm{M})$ \\
\hline SDS & $6.43 \times 10^{-3}$ & $4.1 \times 10^{-3}$ & $2.68 \times 10^{-5}$ & $1.09 \times 10^{-6}$ \\
NP-40 & $6.43 \times 10^{-3}$ & $1.5 \times 10^{-4}$ & $7.42 \times 10^{-4}$ & 0.053 \\
NP-40 & $1.78 \times 10^{-1}$ & $1.5 \times 10^{-4}$ & $7.42 \times 10^{-4}$ & 0.0019 \\
\hline
\end{tabular}


the parameter $N_{\mathrm{h}}$ for the SDS stabilized polymerization system is about two orders of magnitude greater than that for the NP-40 stabilized system.

Based on the results presented in this paper, it is proposed that the steric stabilization effect provided by the pure nonionic surfactant NP-40 is not strong enough to prohibit the interactive particles from flocculating with one another. As a result, depending on the concentration of NP-40, only a small population of latex particles ( $\mathrm{ca} 10^{16}$ per litre of water) or a large particle size ( $c a 200-500 \mathrm{~nm}$ ) can be achieved by using NP-40 as the sole surfactant in the batch emulsion polymerization of STY. On the other hand, the mixed surfactant system (SDS/NP-40) can greatly improve the latex stability via the synergetic effects provided by both the electrostatic and steric stabilization mechanisms and, thereby, retard the extent of the limited flocculation process. This action then can increase the number of latex particles significantly (e.g. $10^{18}$ per litre of water) and reduce the particle size (e.g. $50 \mathrm{~nm}$ ) of the finished batch. The mixed surfactant system SDS/NP-40 $(20 / 80)$ is the best, considering the fact that it results in the best reproducibility of the experiment (i.e. the most stable latex particles during the reaction), and the greatest polymerization rate. However, it should be pointed out that this study can only serve as a qualitative description of the general features of the batch emulsion polymerization of STY stabilized by the mixed surfactant system, SDS/NP-40. To gain a better understanding of the role of the mixed surfactant system, the particle nucleation and growth stages must be decoupled and then investigated independently.

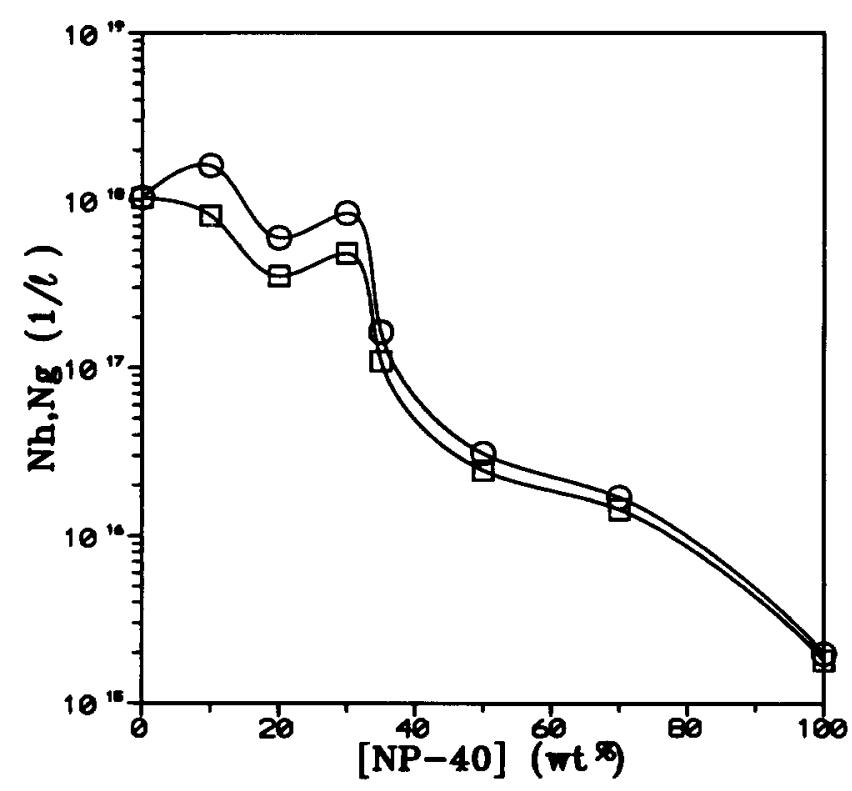

Figure 7 Number of latex particles per litre of water as a function of the $w t \%$ of $\mathrm{NP}-40$ in the mixture: $[\mathrm{S}]=2 \times \mathrm{CMC}\left(80^{\circ} \mathrm{C}\right)$. ( $\left.\square\right) N_{\mathrm{h}}$; (O) $N_{\mathrm{g}}$
Experimental work on these subjects is in progress in our laboratory.

\section{CONCLUSIONS}

The influence of the mixed surfactant system (SDS/NP40) on the batch emulsion polymerization of STY was investigated in this work. The parameter $n$ obtained from the slope of the least-squares-best-fitted $\log \left(N_{\mathrm{h}}\right)$ vs $\log [\mathrm{S}]$ straight line first remains relatively constant (the value of $n$ is around 0.6 ) when [NP-40] is increased from $0 \%$ to $30 \%$, followed by a rapid increase in $n$ to a maximum with [NP-40] being increased from 30 to $80 \%$. The parameter $n$ then decreases rapidly as [NP-40] is increased from 80 to $100 \%$. This kind of behaviour suggests that Smith-Ewart theory is only valid for the emulsion polymerization system containing $30 \mathrm{wt} \% \mathrm{NP}$ 40 or less. The polymerization system deviates from Smith-Ewart theory significantly when [NP-40] is greater than $50 \%$. In addition, the polymerization system deviates the most from Smith-Ewart theory when [NP-40] is equal to $80 \%$, where the parameter $n$ is as high as 1.8 .

For a series of experiments with constant $[\mathrm{S}]$ and $[\mathrm{I}]$, both the monomer conversion' $(X)$ and particle size $\left(d_{\mathrm{p}}\right)$ data taken during polymerization show that the reproducibility of the experiment in the decreasing order is: $[\mathrm{NP}-40]=80 \% \approx[\mathrm{NP}-40]=0 \%>[\mathrm{NP}-40]=50 \% \gg$ $[\mathrm{NP}-40]=100 \%$. For the reaction system stabilized by pure NP-40, the extremely scattered $X$ and $d_{\mathrm{p}}$ data are attributed to the limited flocculation process associated with the relatively unstable latex particles. On the other hand, the mixed surfactant system (SDS/NP-40) containing $20 \mathrm{wt} \%$ SDS or more can be very effective for stabilizing the growing latex particles during polymerization. Thus, the reproducibility of the experimental data is reasonably good. Furthermore, the rate of polymerization display a maximum for the reaction system with $[\mathrm{NP}-40]=80 \%$. The average number of radicals per particle increases with increasing [NP-40] and only the reaction system with $[\mathrm{NP}-40]=50 \%$ follows Smith-Ewart case II kinetics. In addition, the number of latex particles per litre of water produced at the end of polymerization remains relatively constant when [NP-40] is in the range of 0 to $90 \%$, and it drops sharply when [NP-40] is increased from 90 to $100 \%$.

For another series of experiments with [S] being kept at twice the $\mathrm{CMC}\left(80^{\circ} \mathrm{C}\right)$ of the mixed surfactant (SDS/ NP-40) solution, the number of latex particles per litre of water produced at the end of polymerization first remains relatively constant when [NP-40] is below $30 \%$ and, thereafter, it starts to decrease with an increase in [NP-40]. Based on the experimental data shown in this work, it can be concluded that the steric stabilization effect provided by the pure nonionic surfactant (NP-40) is not strong enough to prohibit the interactive particles from flocculating with one another. On the other hand, the mixed surfactant system (SDS/NP-40) can greatly

Table 5 Calculated values of the parameters $N_{\mathrm{m}}, R_{\mathrm{i}} / N_{\mathrm{m}}$, and $N_{\mathrm{h}}:[\mathrm{S}]=2 \times \mathrm{CMC}\left(80^{\circ} \mathrm{C}\right),[\mathrm{I}]=6.43 \times 10^{-3} \mathrm{M}$

\begin{tabular}{llll}
\hline Surfactant & CMC (M) & $N_{\mathrm{m}}(\mathrm{M})$ & $R_{\mathrm{i}} / N_{\mathrm{m}}\left(\mathrm{s}^{-1}\right)$ \\
\hline SDS & $4.1 \times 10^{-3}$ & $5.78 \times 10^{-5}(\mathrm{M})$ & 0.025 \\
NP-40 & $1.5 \times 10^{-4}$ & $1.88 \times 10^{-4}$ & 0.075 \\
\hline
\end{tabular}


improve the latex stability via the synergetic effects provided by both the electrostatic and steric stabilization mechanisms, and thereby reduce the degree of the limited flocculation process. The mixed surfactant system SDS/ NP-40 (20/80) is the best, considering the fact that it results in the best reproducibility of the experiment (i.e. the most stable latex particles during the reaction) and the greatest polymerization rate.

\section{ACKNOWLEDGEMENTS}

The authors would like to thank S. C. Chang, J. Y. Chiu, C. S. Lin, D. J. Chang and W. C. Jian for performing part of the emulsion polymerization experiments. The financial support from National Science Council, Taiwan, Republic of China (NSC82-0113-E-011-170T), is greatly appreciated.

\section{REFERENCES}

1 Deryagnin, B. V. and Landau, L. D. Acta Physicochim. USSR $1941,14,633$

2 Verwey, E. J. W. and Overbeek, J. Th. G. 'Thoery of the Stability of Lyophobic Colloids', Elsevier, New York, 1943

3 Sato, T. and Ruch, R. 'Stabilization of Colloidal Dispersions by Polymer Adsorption', Marcel Dekker, New York, 1980

4 Napper, D. H. 'Polymeric Stabilization of Colloidal Dispersions', Academic Press, London, 1983
5 Harkins, W. D. J. Am. Chem. Soc. 1947, 69, 1428

Smith, W. V. and Ewart, R. W. J. Chem. Phys. 1948, 16, 592 Smith, W. V. J. Am. Chem. Soc. 1948, 70, 3695

Smith, W. V. J. Am. Chem. Soc. 1949, 71, 4077

Woods, M. E., Dodge, J. S. and Krieger I. M. J. Paint Technol. $1968,40,541$

10 Chu, H. and Piirma, I. Polym. Bull. 1989, 21, 301

11 Unzueta, E. and Forcada, J. Polymer 1995, 36, 1045

12 Chern, C. S. and Hsu, H. J. Appl. Polym. Sci. 1995, 55, 571

13 Chern, C. S. and Lin, F. Y. J. Macromol. Sci. Pure Appl. Chem 1996, A33, 1077

14 Lin, S. Y., Chern, C. S., Chen, L. J. and Wu, S. C. Colloid Surface $A$ (in press)

$15 \mathrm{Chu}, \mathrm{H} . \mathrm{H}$. and Cheng, H. C. 'IUPAC International Symposium, Functional and High Performance Polymers' Taipei, Taiwan, 14-16 Nov, 1994, Preprints, p. 413 (paper No. 6-E-13)

16 Odian, G. 'Principles of Polymerization', Wiley, New York, 1981

17 Kolthoff, I. M. and Miller, I. K. J. Am. Chem. Soc. 1951, 73, 3055

18 Matheson, M. S., Auer, E. E., Bevilacqua, E. B. and Hart, E. J. J. Am. Chem. Soc. 1949, 71, 497

19 Soh, S. K. and Sundberg, D. C. J. Polym. Sci., Polym. Chem. Edn. 1982, 20, 1345

20 Lee, H. C. and Poehlein, G. W. Polym. Process Eng. 1987, 5, 37

21 Bartholome, E., Gerrens, H., Herbeck, R. and Weitz, H. M Z. Elektrochem. 1956, 60, 334

Tartar, H. V. J. Phys. Chem. 1955, 59, 1195

23 Venable, R. L. and Nauman, R. V. J. Phys. Chem. 1964, 68, 3498

Becher, P. J. Colloid Sci. 1961, 16, 49

O'Toole, J. I. J. Appl. Polym. Sci. 1965, 9, 1291

Lee, H. C., Ph.D. Dissertation, School of Chemical Engineering, Georgia Institute of Technology, Atlanta, 1985 